\title{
Pathological upgrading in prostate cancer treated with surgery in the United Kingdom: trends and risk factors from the British Association of Urological Surgeons Radical Prostatectomy Registry
}

Nicholas Bullock ${ }^{1,2^{*}}$ (D) Andrew Simpkin ${ }^{3}$, Sarah Fowler ${ }^{4}$, Murali Varma ${ }^{5}$, Howard Kynaston $^{1,2}$ and Krishna Narahari ${ }^{2}$

\begin{abstract}
Background: Accurate grading at the time of diagnosis if fundamental to risk stratification and treatment decision making in patients with prostate cancer. Whilst previous studies have demonstrated significant pathological upgrading and downgrading following radical prostatectomy (RP), these were based on historical cohorts and do not reflect contemporary patient selection and management practices. The aim of this national, multicentre observational study was to characterise contemporary rates and risk factors for pathological upgrading after RP in the United Kingdom (UK).

Methods: All RP entries on the British Association of Urological Surgeons (BAUS) Radical Prostatectomy Registry database of prospectively entered cases undertaken between January 2011 and December 2016 were extracted. Those patients with full preoperative PSA, clinical stage, needle biopsy and subsequent RP pathological grade information were included. Upgrade was defined as any increase in Gleason grade from initial needle biopsy to pathological assessment of the entire surgical specimen. Statistical analysis and multivariate logistic regression were undertaken using R version 3.5 (R Foundation for Statistical Computing, Vienna, Austria).

Results: A total of 17,598 patients met full inclusion criteria. Absolute concordance between initial biopsy and pathological grade was $58.9 \%(n=10,364)$, whilst upgrade and downgrade rates were $25.5 \%(n=4489)$ and $15.6 \%$ $(n=2745)$ respectively. Upgrade rate was highest in those with D'Amico low risk compared with intermediate and high-risk disease (55.7\% versus 19.1 and $24.3 \%$ respectively, $P<0.001)$. Although rates varied between year of surgery and geographical regions, these differences were not significant after adjusting for other preoperative diagnostic variables using multivariate logistic regression.

Conclusions: Pathological upgrading after RP in the UK is lower than expected when compared with other large contemporary series, despite operating on a generally higher risk patient cohort. As new diagnostic techniques that may reduce rates of pathological upgrading become more widely utilised, this study provides an important benchmark against which to measure future performance.
\end{abstract}

Keywords: Gleason grade, Needle biopsy, Pathological, Prostate cancer, Radical prostatectomy

\footnotetext{
* Correspondence: bullocknp@cardiff.ac.uk

1 Division of Cancer and Genetics, Cardiff University School of Medicine, Cardiff, UK

2Department of Urology, Cardiff and Vale University Health Board, University Hospital of Wales, Cardiff, UK

Full list of author information is available at the end of the article
}

(c) The Author(s). 2019 Open Access This article is distributed under the terms of the Creative Commons Attribution 4.0 International License (http://creativecommons.org/licenses/by/4.0/), which permits unrestricted use, distribution, and reproduction in any medium, provided you give appropriate credit to the original author(s) and the source, provide a link to the Creative Commons license, and indicate if changes were made. The Creative Commons Public Domain Dedication waiver (http://creativecommons.org/publicdomain/zero/1.0/) applies to the data made available in this article, unless otherwise stated. 


\section{Background}

Despite first being described over fifty years ago, Gleason score has stood the test of time and remains one of the most powerful prognostic indicators in patients undergoing radical treatment with curative intent [1-5]. The Gleason grading system was updated in 2005 and again in 2014 following consensus conferences of the International Society of Urological Pathology (ISUP) $[6,7]$. In the more recent update, the ISUP supported adoption of a validated Grade Group stratification system ranging from 1 (Gleason score $\leq 6)$ to 5 (Gleason score 9 or 10 ), to be used in conjunction with the overall Gleason system in order to simplify the number of grading categories and facilitate more accurate stratification of disease [6].

Despite advances in recent years, conventional diagnostic pathways employ transrectal ultrasound (TRUS) guided prostate biopsy to acquire systematic needle biopsies of the prostate, which has recently been shown to have a sensitivity of only $48 \%$ for the diagnosis of 'clinically significant' cancer, defined as Gleason score of at least $4+3$ or a maximum core length of at least $6 \mathrm{~mm}$ [8]. Given the heterogeneity of disease it is not surprising that a significant proportion of cases are upgraded following radical prostatectomy (RP) compared with the initial TRUS biopsy [9-11]. This has wide ranging implications, as it may potentially lead to undertreatment of those that are undergraded by the initial biopsy, or conversely, overtreatment of those that have been overgraded. Furthermore, upgrading has been associated with adverse pathological outcomes, such as positive surgical margin status and biochemical recurrence [12, 13].

Whilst a small number of studies have reported pathological upgrading rates following RP in large patient populations, these utilised historical cohorts that underwent surgery prior to 2012 [10, 11]. Furthermore, neither involved participants from the United Kingdom (UK), thereby limiting the generalisability of findings to this patient population and the National Health Service. This is of particular importance as, owing to differences in screening practices across Europe and North America, a relatively high proportion of patients present with advanced disease at the time of diagnoses in the UK [14-18].

The objective of this large observational study was to characterise contemporary rates of pathological upgrading after RP in the UK and identify risk factors for upgrading within this population.

\section{Methods}

\section{Case selection}

Data for patients undergoing radical prostatectomy in the UK were uploaded prospectively by individual surgeons or institutions onto the British Association of Urological Surgeons (BAUS) Radical Prostatectomy Registry database. All patients that underwent RP between 1st January 2011 and 31st December 2016 were eligible for inclusion. Patients with missing data for key variables such as preoperative Prostate Specific Antigen (PSA), initial biopsy Gleason grade, clinical $\mathrm{T}$ stage or final RP Gleason grade were excluded, as were those that underwent salvage surgery.

\section{Pathological assessment}

The time from initial biopsy to RP was not recorded in the database. However, in the UK the National Health Service Cancer Reform Strategy states that patients diagnosed with cancer should receive definitive treatment within 31 days of the decision to do so. This means that most patients will have undergone surgery within 1-2 months of the initial biopsy, thereby ameliorating potential for genuine grade progression between histological assessment of the biopsy and surgical specimen.

Whilst the exact type of initial prostate biopsy was not recorded, TRUS guided biopsy utilising an extended sampling approach was standard practice across the UK during the study period. All biopsies were evaluated and reported by a Consultant Pathologist with or without expertise in urological pathology. Almost all RP specimens were examined and reported by a Consultant Pathologist with expertise in urological pathology. No cases were re-reviewed for the purposes of this study. The primary outcome was upgrading, defined as any increase in Gleason grade between the initial biopsy and final RP histology.

\section{Statistical analysis}

Continuous variables were reported using mean, median and range, and categorical variables as percentages. For unadjusted comparison between upgraded and nonupgraded cases, Chi-squared and t-tests were used to assess for statistically significant differences in categorical and continuous variables respectively. Logistic regression was used to formally determine the association of key preoperative variables and upgrading, with the odds ratio for each being reported alongside a 95\% confidence interval and $p$-value. D'Amico risk category was not included in the mutually adjusted model, since it is a composite variable derived from PSA, clinical T-stage and biopsy Gleason grade (all of which were included in the model). All analyses were performed in R v3.5 ( $R$ Core Team (2018). R: A language and environment for statistical computing. R Foundation for Statistical Computing, Vienna, Austria).

\section{Results}

\section{Patient demographics}

17,598 of 30,424 patients that were entered onto the registry between 1st January 2011 and 31st December 2016 met full inclusion criteria. Table 1 demonstrates 
Table 1 Patient, disease and operative characteristics

Patient and disease characteristics
Age (years)
Mean
Median
Range
Preoperative PSA (ng/ml)
Mean
Median
Range
Preoperative biopsy ISUP Grade Group (\%)
1
2
3
4
5
Preoperative clinical stage (\%)
T1
T2
T3
T4

Preoperative D'Amico risk group (\%)

Low risk

Intermediate risk

High risk

Operative characteristics

Year of surgery (\%)

2011

2012

2013

2014

2015

2016

Region (\%)

A

B

C

D

E

F

G

H

।

J

K

L
Table 1 Patient, disease and operative characteristics (Continued)

\begin{tabular}{ll}
\hline$M$ & $745(4.2)$ \\
$N$ & $1798(10.2)$ \\
$O$ & $324(1.8)$ \\
$P$ & $302(1.7)$ \\
\hline
\end{tabular}

the patient and operative characteristics. Mean age and preoperative PSA were 63.2 years and $10.06 \mathrm{ng} / \mathrm{ml}$ respectively. The majority of cases were performed for D'Amico high risk disease $(52.7 \% ; n=1766)$, with only $10 \%(n=1766)$ for low risk disease. The proportion of cases performed each year increased from 2011 to 2016, owing to both a yearly increase in the number of cases entered onto the registry together with a reduction in the number of cases excluded on account of missing data each year.

\section{Pathological upgrade rates}

$5435(30.9)$

$8311(47.2)$

$3839(21.8)$

$13(0.10$

$1766(10.0)$

$6563(37.3)$

$9269(52.7)$

$1001(5.7)$

$1159(6.6)$

$2259(12.8)$

$3783(21.5)$

$4566(25.9)$

$4830(27.4)$

$79(0.4)$

$701(4.0)$

$1653(9.4)$

$2081(11.8)$

$706(4.0)$

$2084(11.8)$

$1315(7.5)$

$29(0.2)$

$67(0.4)$

$2093(11.9)$

1885 (10.7)

$1736(9.9)$

Absolute concordance between initial biopsy and pathological Gleason grade was 58.9\% $(n=10,364)$, whilst upgrade and downgrade rates were $25.5 \%(n=4489)$ and $15.6 \%(n=2745)$ respectively. Table 2 demonstrates concordance between the initial biopsy and final RP histology as stratified by ISUP Grade Groups. Concordance was lowest in those patients with Grade Group 1 and 4 on initial biopsy (39.6 and $25.4 \%$ respectively), whilst highest in those patients with Grade Group 2 (76.6\%). An increase by one ISUP Grade Group (for example, from Grade Group 1 on initial biopsy to Grade Group 2 on final RP histopathology) constituted the majority of upgrading events, with 319 (8.2\%), 286 (3.4\%) and 181 (6.3\%) cases being upgraded by two or more Grade Groups in patients with Grade Group 1, 2 and 3 on initial biopsy respectively.

\section{Risk factors for pathological upgrading}

Table 3 provides the association between patient and operative characteristics and pathological upgrading. Upgrading was associated with a higher preoperative PSA $(10.8 \mathrm{ng} / \mathrm{ml}$ versus $9.81 \mathrm{ng} / \mathrm{ml} ; p<0.001)$ and reduced over time, with $30.6 \%$ of cases being upgraded in 2011 compared with $23.2 \%$ in 2016 (Fig. 1a; p < 0.001). Of note, upgrade rate was highest in those with D'Amico low risk compared with intermediate and high-risk disease (Fig. 1b; 55.7\% versus 19.1 and $24.3 \%$ respectively, $P$ $<0.001)$. There was considerable variation in upgrading between regions, with rates ranging from $13.9 \%$ in region $\mathrm{A}$ to $37.9 \%$ in region $\mathrm{H}$ (Fig. 1c; $\mathrm{P}<0.001$ ).

Table 4 gives the results of the mutually adjusted logistic regression analysis for upgrading. After adjusting for differences in other characteristics, both increased age and preoperative PSA were associated with increased 
Table 2 Concordance between the initial biopsy and final RP histology when stratified by ISUP Grade Groups

\begin{tabular}{|c|c|c|c|c|c|c|c|c|c|c|}
\hline \multirow[t]{3}{*}{ RP ISUP Grade Group } & \multicolumn{10}{|c|}{ Biopsy ISUP Grade Group } \\
\hline & \multicolumn{2}{|c|}{$1(\leq 6)$} & \multicolumn{2}{|c|}{$2(3+4)$} & \multicolumn{2}{|c|}{$3(4+3)$} & \multicolumn{2}{|l|}{$4(8)$} & \multicolumn{2}{|c|}{$5(9-10)$} \\
\hline & No. & $\%$ & No. & $\%$ & No. & $\%$ & No. & $\%$ & No. & $\%$ \\
\hline $1(\leq 6)$ & 1550 & 39.6 & 430 & 5.2 & 38 & 1.3 & 21 & 1.5 & 2 & 0.2 \\
\hline $2(3+4)$ & 2045 & 52.2 & 6381 & 76.6 & 955 & 33.0 & 351 & 24.6 & 103 & 9.9 \\
\hline $3(4+3)$ & 235 & 6.0 & 1231 & 14.8 & 1579 & 54.6 & 486 & 34.1 & 227 & 21.9 \\
\hline 4 (8) & 52 & 1.3 & 165 & 2.0 & 140 & 4.8 & 363 & 25.4 & 73 & 7.0 \\
\hline $5(9-10)$ & 32 & 0.8 & 121 & 1.5 & 181 & 6.3 & 206 & 14.4 & 631 & 60.9 \\
\hline Total & 3914 & 100 & 8328 & 100 & 2893 & 100 & 1427 & 100 & 1036 & 100 \\
\hline
\end{tabular}

odds of pathological upgrading (OR 1.022; $p<0.001$ per year and OR 1.026; $\mathrm{p}<0.001$ per $\mathrm{ng} / \mathrm{ml}$ respectively). Higher initial biopsy ISUP Grade Groups were associated with lower odds of upgrading, whilst clinically T2 and T3 tumours had the highest odds of upgrading. Those cases performed in more recent years were associated with reduced odds of upgrading when compared with 2011, although all failed to reach significance. Likewise, despite apparent regional differences, almost all failed to reach significance.

\section{Discussion}

This is the largest study to date exploring pathological upgrading after radical prostatectomy, as well as the first of its kind conducted within a large contemporary UK patient cohort. There are several potential reasons for differences occurring between initial biopsy Gleason grade and that of the RP specimen. Whilst genuine grade progression in the time between initial biopsy and $\mathrm{RP}$ is possible, this is unlikely and thus the majority of discrepancy occurs as a result of either sampling error or variation in pathological reporting.

Sampling error occurs when an area of high-grade tumour is missed by the initial needle biopsy, leading to undergrading. Conversely, the biopsy may oversample the high-grade component of a tumour. This scenario is well described, with many studies demonstrating conventional TRUS guided prostate biopsy to be poor at localising the index tumour and/or estimating true tumour grade [9-11, 19].

Variation in pathological reporting may result from the inherent subjectivity of tumour grading, microscopic interpretation issues and differences in rules used to report the Gleason score. Tumour grade is a morphological and biological continuum with arbitrary cut-offs, so a degree of variation is inevitable in borderline cases. Microscopic interpretation such as distinction between poorly formed glands of pattern 4 and tangential sectioning of pattern 3 glands is also subjective [10].

A number of authors have therefore sought to quantify the level of inter-observer agreement among pathologists
$[20,21]$, with one recent study demonstrating kappa values of 0.61 for needle biopsies and 0.37 for RP specimens between the original pathology report and a 'gold standard' report issued by expert urological pathologists [22]. This study also recognised that the accuracy of Gleason grading may depend on the level of experience and training of the reporting pathologist [22]. Whilst the differing service structure means the findings of many of these US based studies cannot be completely applied to the UK, inter-observer variability will no doubt be partially responsible for some of the grade changes seen in the current series. For example, whilst several cases were upgraded following RP, a significant number were also downgraded, most notably from ISUP Grade Group 3 to 2 and from Grade Group 4 to either 3 or 2. In the UK many initial needle biopsies are reported in smaller District General Hospitals by pathologists who may or may not have expertise in urological pathology, whilst almost all RP specimens are reported in larger tertiary referral centres by expert urological pathologists. It is therefore possible that some of the observed overcalling of Gleason pattern 4 may have arisen due to lack of awareness among general UK pathologists of the 2014 ISUP consensus conference recommendation that occasional/ seemingly poorly formed or fused glands are insufficient for a diagnosis of pattern 4 [6]. Finally, even when pathologists agree on the grade, they may report the Gleason score differently. For example, when cores show different Gleason scores, contemporary practice varies with either the overall (global) or worst Gleason score recorded for each biopsy series [7, 23, 24].

In this cohort of 17,598 patients we found overall upgrade and downgrade rates of 25.5 and $15.6 \%$ respectively. Interestingly upgrade rate was highest in those patients undergoing RP for low risk prostate cancer, as classified using D'Amico criteria that are widely used in UK practice [25]. Whilst this is somewhat expected given that this group comprises patients with Gleason 3 $+3=6$ disease on initial biopsy, for whom the only change in grade can be upgrading, the rate of $55.7 \%$ is higher than reported in other comparable series. Whilst 
Table 3 Association between patient, disease and operative characteristics and pathological upgrading after RP

\begin{tabular}{|c|c|c|c|}
\hline Characteristic & No upgrade $(n=13,109)$ & Upgrade $(n=4489)$ & $p$-value \\
\hline Age (years) & $63.2(6.56)$ & $63.3(6.44)$ & 0.159 \\
\hline Preoperative PSA (ng/ml) & $9.81(7.93)$ & $10.8(8.94)$ & $<0.001$ \\
\hline Preoperative biopsy ISUP Grade Group & & & $<0.001$ \\
\hline 1 & $1550(39.6 \%)$ & $2364(60.4 \%)$ & \\
\hline 2 & $6811(81.8 \%)$ & $1517(18.2 \%)$ & \\
\hline 3 & 2572 (88.9\%) & $321(11.1 \%)$ & \\
\hline 4 & $1213(85.0 \%)$ & $214(15.0 \%)$ & \\
\hline 5 & $963(93.0 \%)$ & $73(7.05 \%)$ & \\
\hline Preoperative clinical stage & & & $<0.001$ \\
\hline T1 & $3957(72.8 \%)$ & $1478(27.2 \%)$ & \\
\hline $\mathrm{T} 2$ & $6350(76.4 \%)$ & $1961(23.6 \%)$ & \\
\hline T3 & $2792(72.7 \%)$ & 1047 (27.3\%) & \\
\hline T4 & $10(76.9 \%)$ & $3(23.1 \%)$ & \\
\hline Preoperative D'Amico risk group & & & $<0.001$ \\
\hline Low risk & $782(44.3 \%)$ & $984(55.7 \%)$ & \\
\hline Intermediate risk & $5307(80.9 \%)$ & $1256(19.1 \%)$ & \\
\hline High risk & 7020 (75.7\%) & $2249(24.3 \%)$ & \\
\hline Year of surgery & & & $<0.001$ \\
\hline 2011 & $695(69.4 \%)$ & $306(30.6 \%)$ & \\
\hline 2012 & $848(73.2 \%)$ & 311 (26.8\%) & \\
\hline 2013 & 1602 (70.9\%) & 657 (29.1\%) & \\
\hline 2014 & 2835 (74.9\%) & 948 (25.1\%) & \\
\hline 2015 & 3420 (74.9\%) & 1146 (25.1\%) & \\
\hline 2016 & 3709 (76.8\%) & 1121 (23.2\%) & \\
\hline Region & & & $<0.001$ \\
\hline A & 68 (86.1\%) & 11 (13.9\%) & \\
\hline B & $544(77.6 \%)$ & 157 (22.4\%) & \\
\hline$C$ & 1239 (75.0\%) & 414 (25.0\%) & \\
\hline $\mathrm{D}$ & $1643(79.0 \%)$ & $438(21.0 \%)$ & \\
\hline E & $552(78.2 \%)$ & $154(21.8 \%)$ & \\
\hline $\mathrm{F}$ & $1536(73.7 \%)$ & $548(26.3 \%)$ & \\
\hline G & 1020 (77.6\%) & 295 (22.4\%) & \\
\hline $\mathrm{H}$ & $18(62.1 \%)$ & 11 (37.9\%) & \\
\hline I & 49 (73.1\%) & 18 (26.9\%) & \\
\hline J & 1553 (74.2\%) & $540(25.8 \%)$ & \\
\hline K & 1382 (73.3\%) & $503(26.7 \%)$ & \\
\hline L & 1301 (74.9\%) & 435 (25.1\%) & \\
\hline M & 505 (67.8\%) & 240 (32.2\%) & \\
\hline$N$ & $1246(69.3 \%)$ & $552(30.7 \%)$ & \\
\hline $\mathrm{O}$ & 226 (69.8\%) & 98 (30.2\%) & \\
\hline$P$ & 227 (75.2\%) & 75 (24.8\%) & \\
\hline
\end{tabular}

this may have implications for counselling men with low risk disease that are considering surveillance, we must be wary not to extrapolate this figure to all patients. In the UK, recent years have seen a reduction in the number of men with low risk disease that undergo radical treatment [14], which is reflected within our cohort $(n=$ 


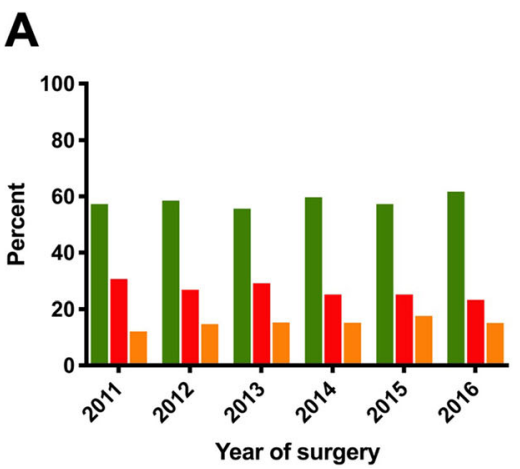

C

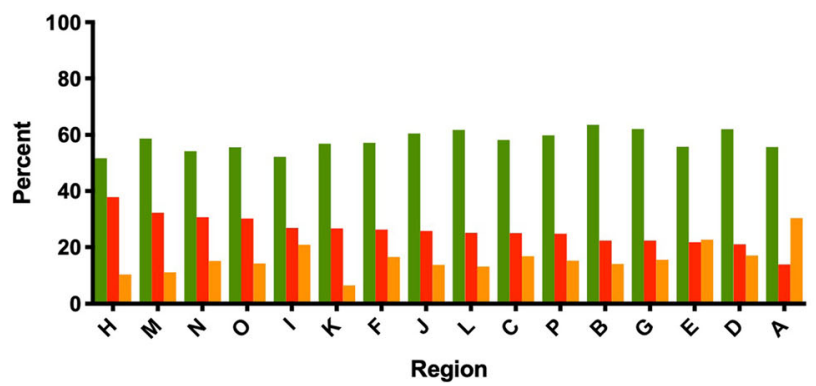

B

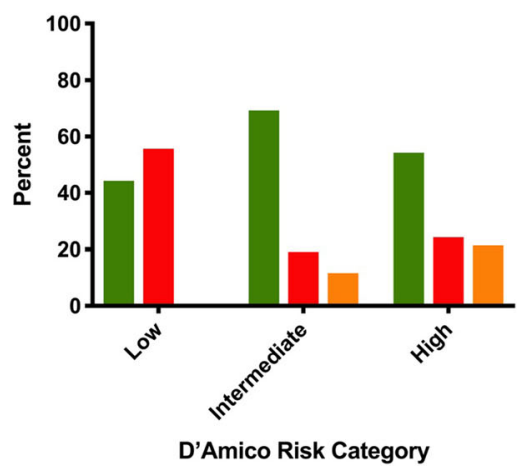

Fig. 1 Grade change according to: a, year of surgery. b, D'Amico risk category. c, anonymised region, ranked in order of upgrade rate

1766; 10\%). This means those patients with low risk disease that undergo RP are likely to have other 'high risk' features, such as large volume tumour.

This study also demonstrated a reduction in upgrading in more recent years, with the rate falling from $30.6 \%$ in 2011 to $23.2 \%$ in 2016. Furthermore, we also identified variation in upgrading between geographical regions, with rates ranging from $13.9 \%$ in region $\mathrm{A}$ to $37.9 \%$ in region $\mathrm{H}$. However, when adjusting for differences in other preoperative variables, almost all differences between regions and years of surgery failed to reach significance. Collectively this means that such differences can be explained by variation in other factors such as increasing age, preoperative PSA and clinical stage, as well as decreasing biopsy ISUP Grade Group, all of which were found to be significant risk factors for upgrading in our mutually adjusted logistic regression model.

Whilst TRUS guided biopsy utilising an extended sampling approach was standard practice across the UK during the study period, the exact biopsy technique utilised in each case was not recorded in the registry. Recent years have seen a trend towards increased uptake of prebiopsy mpMRI and contemporary diagnostic techniques such as mpMRI influenced biopsy strategy, template guided transperineal biopsy and mpMRI-TRUS fusion biopsy, which have been shown to reduce pathological upgrading after surgery [26-28]. Furthermore, these techniques have also been shown to reduce diagnosis of 'clinically insignificant' cancers, such as those that are Gleason $3+3$ [29]. Collectively this may explain the trend towards a reduction in upgrading in seen in more recent years in this series. Furthermore, as these techniques continue to become more widely utilised, future rates of pathological upgrading are likely to decrease, thereby rendering this study an important benchmark against which to measure performance.

A number of other studies have explored upgrading and downgrading following RP. Whilst many of these utilised small historical cohorts, the results of the two largest and most recent series may be compared to the findings presented here. The first of these, published by Epstein et al. in 2012, reported grade change in 7643 US patients that underwent surgery between 2002 and 2010 [10]. Although similar in terms of age, the cohort had a lower PSA and higher proportion of T1 and Gleason 6 disease, thus representing a lower risk population. Interestingly the authors report an upgrade rate of $36.3 \%$ from Gleason 5-6 to a higher grade after RP, representing a higher concordance in this group compared with the present study (63.7\% versus $39.6 \%$ respectively). The reasons for these differences are likely multifactorial but may be due to the small proportion of patients with initial biopsy Gleason 6 undergoing surgery within our cohort, along with the likelihood of this group possessing 
Table 4 Mutually adjusted logistic regression analysis for pathological upgrading after RP

\begin{tabular}{|c|c|c|}
\hline Characteristic & Odds ratio ( $95 \%$ confidence interval) & $p$-value \\
\hline Age & $1.022(1.016-1.028)$ & $<0.001$ \\
\hline Preoperative PSA & $1.026(1.022-1.031)$ & $<0.001$ \\
\hline \multicolumn{3}{|c|}{ Preoperative biopsy ISUP Grade Group } \\
\hline 1 (reference) & 1 & \\
\hline 2 & $0.123(0.112-0.135)$ & $<0.001$ \\
\hline 3 & $0.057(0.049-0.065)$ & $<0.001$ \\
\hline 4 & $0.085(0.072-0.101)$ & $<0.001$ \\
\hline 5 & $0.030(0.023-0.039)$ & $<0.001$ \\
\hline \multicolumn{3}{|c|}{ Preoperative clinical stage } \\
\hline T1 (reference) & 1 & \\
\hline $\mathrm{T} 2$ & $1.231(1.120-1.353)$ & $<0.001$ \\
\hline T3 & $1.990(1.774-2.232)$ & $<0.001$ \\
\hline T4 & $1.199(0.275-5.237)$ & 0.809 \\
\hline \multicolumn{3}{|l|}{ Year of surgery } \\
\hline 2011 (reference) & 1 & \\
\hline 2012 & $0.930(0.749-1.156)$ & 0.514 \\
\hline 2013 & $1.084(0.896-1.311)$ & 0.408 \\
\hline 2014 & $0.851(0.710-1.021)$ & 0.082 \\
\hline 2015 & $0.935(0.782-1.118)$ & 0.462 \\
\hline 2016 & $0.908(0.759-1.086)$ & 0.289 \\
\hline \multicolumn{3}{|l|}{ Region } \\
\hline A & $0.792(0.403-1.556)$ & 0.498 \\
\hline B & $1.077(0.857-1.353)$ & 0.526 \\
\hline C & $1.071(0.906-1.265)$ & 0.421 \\
\hline $\mathrm{D}$ & $0.980(0.834-1.152)$ & 0.808 \\
\hline$E$ & $0.886(0.704-1.115)$ & 0.303 \\
\hline $\mathrm{F}$ & $1.152(0.984-1.348)$ & 0.078 \\
\hline G & $0.891(0.743-1.068)$ & 0.210 \\
\hline $\mathrm{H}$ & $1.980(0.840-4.669)$ & 0.118 \\
\hline । & $1.299(0.688-2.452)$ & 0.420 \\
\hline $\mathrm{J}(\text { reference })^{a}$ & 1 & \\
\hline K & $0.830(0.706-0.976)$ & 0.024 \\
\hline$L$ & $0.863(0.731-1.020)$ & 0.084 \\
\hline M & $0.837(0.678-1.033)$ & 0.098 \\
\hline $\mathrm{N}$ & $1.132(0.963-1.330)$ & 0.133 \\
\hline $\mathrm{O}$ & $0.995(0.741-1.338)$ & 0.976 \\
\hline$P$ & $0.654(0.477-0.897)$ & 0.008 \\
\hline
\end{tabular}

${ }^{\mathrm{a}}$ Region $\mathrm{J}$ chosen as a reference owing to largest number of patients

additional high-risk features that would have favoured this treatment approach. However, despite these differences, there was agreement that both increasing age and preoperative PSA were predictors of upgrading [10].

More recently, Danneman et al. reported upgrading within a cohort of 15,598 patients from the Swedish
National Prostate Cancer Register that underwent RP between 2000 and 2012 [11]. Inclusion criteria restricted analysis to patients less than 70 with T1-2 disease and a serum PSA of $<20 \mathrm{ng} / \mathrm{ml}$, thereby again comprising a lower risk population than represented here. The authors report an upgrade rate of 35\% from Gleason 2-6 to a higher grade after RP, giving a concordance of $65 \%$ in this group. Once again this is much higher than the present study and may similarly be due to differences in patient demographics.

The strengths of this study lie in the large cohort and its origin from a national level data registry. Furthermore, unlike similar studies, all patients were treated between 2011 and 2016, thereby representing more contemporary patient selection and management practices. This is particularly relevant to the UK, where reducing numbers of patients with low risk disease are undergoing radical intervention each year [14].

This study does however have a number of limitations, including the surgeon/institution reported nature of the data registry. Although a large proportion of the total number of patients that undergo RP in UK are entered, some regions report few numbers and it is possible there are differences between those patients that are entered and those that are not. Another limitation is the amount of missing preoperative data, which led to the exclusion of a number of cases from the full analysis. This is a recognised issue with the BAUS Radical Prostatectomy Registry that must be acknowledged but has not prevented meaningful observations being reported [30, 31]. The type of initial biopsy performed was also unclear, as was whether the overall or worst Gleason score had been recorded in each case. However, these scores are different in only a minority of cases and previous studies have demonstrated that both are clinically comparable [32] Finally, the registry lacked additional pathological parameters that have previously been linked to risk of upgrading, including prostate size $[10,12]$ and extent of cancer in the biopsy $[10,13]$.

\section{Conclusions}

Pathological upgrading after RP remains an important consideration in the management of patients with prostate cancer. This large study demonstrates that overall upgrading in the UK is lower than expected, with risk factors including increasing age, preoperative PSA, and clinical stage. As new diagnostic techniques that may reduce rates of pathological upgrading become more widely utilised, this study will provide an important benchmark against which to measure performance.

Abbreviations

BAUS: British Association of Urological Surgeons; ISUP: International Society of Urological Pathology; mpMRl: multi-parametric magnetic resonance imaging; PSA: Prostate Specific Antigen; RP: Radical prostatectomy; 
TRUS: Transrectal ultrasound; UK: United Kingdom; US: United States of America

\section{Acknowledgements}

The authors would like to acknowledge the BAUS Section of Oncology for allowing access to the data for the purposes of this study, as well as all of the UK Urological Surgeons who contribute to the BAUS Radical Prostatectomy Registry.

\section{Authors' contributions}

KN and NB were responsible for study inception and design. SF was responsible for data acquisition and $\mathrm{NB}, \mathrm{AS}$ and $\mathrm{KN}$ undertook the subsequent analysis. NB, KN, HK and MV were responsible for interpretation of the data and drafting of the manuscript. All authors approved the final manuscript version prior to submission.

\section{Funding}

None.

\section{Availability of data and materials}

The BAUS Radical Prostatectomy Registry data that support the findings of this study are held centrally by the British Association of Urological Surgeons and are not publicly available. A request for use of data may be made via formal application to the BAUS Data \& Audit Manager.

\section{Ethics approval and consent to participate}

The BAUS Radical Prostatectomy Registry has Section 251 approval (Section 251 of the NHS Act 2006) from the Confidentiality Advisory Group of the NHS Health Service Research Authority which permits the collection of NHS patient identifiable information for essential NHS activities and research, without the specific consent of patients. The registry is managed centrally by the BAUS Data and Audit Manager. Applications for use of anonymised patient data are submitted to the BAUS Data and Audit Manager and are subsequently reviewed by the BAUS Section of Oncology Executive Committee. If approved, anonymised data is then released to the applicant for the purposes defined in the application. Approval for the current study was granted by the BAUS Section of Oncology Executive Committee on 7 March 2018.

\section{Consent for publication}

Not applicable.

\section{Competing interests}

The authors declare that they have no competing interests.

\section{Author details}

${ }^{1}$ Division of Cancer and Genetics, Cardiff University School of Medicine, Cardiff, UK. ²Department of Urology, Cardiff and Vale University Health Board, University Hospital of Wales, Cardiff, UK. ${ }^{3}$ School of Mathematics, Statistics and Applied Mathematics, National University of Ireland, Galway, Ireland. ${ }^{4}$ British Association of Urological Surgeons, London, UK. ${ }^{5}$ Department of Cellular Pathology, Cardiff and Vale University Health Board, University Hospital of Wales, Cardiff, UK.

Received: 21 June 2019 Accepted: 24 September 2019 Published online: 17 October 2019

\section{References}

1. Mellinger GT, Gleason D, Bailar J III. The histology and prognosis of prostatic cancer. J Urol. 1967;97:331-7.

2. Epstein J, Partin AW, Sauvageot J, Walsh PC. Prediction of progression following radical prostatectomy: a multivariate analysis of 721 men with long-term follow-up. Am J Surg Pathol. 1996;20:286-92.

3. Albertsen PC, Hanley JA, Gleason DF, Barry MJ. Competing risk analysis of men aged 55 to 74 years at diagnosis managed conservatively for clinically localized prostate cancer. JAMA. 1998;280:975-80.

4. Egevad L, Granfors T, Karlberg L, Bergh A, Stattin P. Prognostic value of the Gleason score in prostate cancer. BJU Int. 2002;89:538-42.

5. Barry MJ, Albertsen PC, Bagshaw MA, Blute ML, Cox R, Middleton RG, Gleason DF, Zincke H, Bergstralh EJ, Jacobsen SJ. Outcomes for men with clinically nonmetastatic prostate carcinoma managed with radical prostactectomy, external beam radiotherapy, or expectant management: a retrospective analysis. Cancer. 2001;91:2302-14.

6. Epstein JI, Egevad L, Amin MB, Delahunt B, Srigley JR, Humphrey PA. The 2014 International Society of Urological Pathology (ISUP) consensus conference on Gleason grading of prostatic carcinoma. Am J Surg Pathol. 2016;40:244-52

7. Epstein Jl, Allsbrook WC Jr, Amin MB, Egevad LL, ISUP Grading Committee The 2005 International Society of Urological Pathology (ISUP) consensus conference on Gleason grading of prostatic carcinoma. Am J Surg Pathol. 2005;29:1228-42.

8. Ahmed HU, Bosaily AE-S, Brown LC, Gabe R, Kaplan MK, Collaco-Moraes Y, Ward K, Hidley RG, Freeman A, Kirkham AP, Oldroyd R, Parker C, Emberton M. PROMIS study group. Diagnostic accuracy of multi-parametric MRI and TRUS biopsy in prostate cancer (PROMIS): a paired validating confirmatory study. Lancet. 2017:389:815-22.

9. Cohen MS, Hanley RS, Kurteva T, Ruthazer R, Silverman ML, Sorcini A, Hamawy K, Roth RA, Tuerk I, Libertino JA. Comparing the Gleason prostate biopsy and Gleason prostatectomy grading system: the Lahey Clinic Medical Center experience and an international meta-analysis. Eur Urol. 2008;54:371-81.

10. Epstein Jl, Feng Z, Trock BJ, Pierorazio PM. Upgrading and downgrading of prostate cancer from biopsy to radical prostatectomy: incidence and predictive factors using the modified Gleason grading system and factoring in tertiary grades. Eur Urol. 2012;61:1019-24.

11. Danneman D, Drevin L, Delahunt B, Samaratunga H, Robinson D, Bratt O, Loeb S, Stattin P, Egevad L. Accuracy of prostate biopsies for predicting Gleason score in radical prostatectomy specimens: nationwide trends 20002012. BJU Int. 2017;119:50-6.

12. Davies JD, Aghazadeh MA, Phillips S, Salem S, Chang SS, Clark PE, Cookson MS, Davis R, Herrell SD, Penson DF, Smith JA, Barocas DA. Prostate size as a predictor of Gleason score upgrading in patients with low risk prostate cancer. J Urol. 2011;186:2221-7.

13. Freedland SJ, Kane CJ, Amling CL, Aronson WJ, Terris MK, Presti JC, SEARCH Database Study Group. Upgrading and downgrading of prostate needle biopsy specimens: risk factors and clinical implications. Urology. 2007;69:495-9.

14. National Prostate Cancer Audit. Patient Summary 2018 - Fourth Year Annual Report. London: Royal College of Surgeons of England. 2018:1-6.

15. Helgstrand JT, Røder MA, Klemann N, Toft BG, Lichtensztajn DY, Brooks JD, Brasso K, Vainer B, Iversen P. Trends in incidence and 5-year mortality in men with newly diagnosed, metastatic prostate cancer-A populationbased analysis of 2 national cohorts. Cancer. 2018;124:2931-8.

16. Brawley OW. Trends in prostate cancer in the United States. J Natl Cancer Inst Monogr. 2012;2012:152-6.

17. Zakaria AS, Dragomir A, Brimo F, Kassouf W, Tanguay S, Aprikian A. Changes in the outcome of prostate biopsies after preventive task force recommendation against prostate-specific antigen screening. BMC Urol. 2018;18:69.

18. Jegerlehner S, Chiolero A, Aujesky D, Rodondi N, Germann S, Konzelmann I, Bulliard JL, NICER. Working Group. Recent incidence and surgery trends for prostate cancer: Towards an attenuation of overdiagnosis and overtreatment? PLoS One. 2019;14:e0210434.

19. Sinnott M, Falzarano SM, Hernandez AV, Jones JS, Klein EA, Zhou M, MagiGalluzzi C. Discrepancy in prostate cancer localization between biopsy and prostatectomy specimens in patients with unilateral positive biopsy: implications for focal therapy. Prostate. 2012;72:1179-86.

20. Allsbrook WC Jr, Mangold KA, Johnson MH, Lane RB, Amin MB, Bostwick DG, Humphrey PA, Jones EC, Reuter VE, Sakr W, Sesterhenn IA, Troncoso P, Wheeler TM, Epstein JI. Interobserver reproducibility of Gleason grading of prostatic carcinoma: urologic pathologists. Hum Pathol. 2001;32:74-80.

21. Melia J, Moseley R, Ball R, Griffiths DF, Grigor K, Harnden P, Jarmulowicz M, McWilliam L, Montironi R, Waller M, Moss S, Parkinson MC. A UK-based investigation of inter-and intra-observer reproducibility of Gleason grading of prostatic biopsies. Histopathology. 2006;48:644-54.

22. Goodman M, Ward KC, Osunkoya AO, Datta MW, Luthringer D, Young AN, Marks K, Cohen V, Kennedy JC, Harber MJ, Amin MB. Frequency and determinants of disagreement and error in gleason scores: A populationbased study of prostate cancer. Prostate. 2012;72:1389-98.

23. Varma M, Berney D, Oxley J, Trpkov K. Gleason Score assignment is the sole responsibility of the pathologist. Histopathology. 2018;73:5-7.

24. The Royal College of Pathologists. Datasets for histopathology reports for prostatic carcinoma. Standards and datasets for reporting cancers. London: Royal College of Pathologists. 2016:60. 
25. D'amico AV, Whittington R, Malkowicz SB, Schultz D, Blank K, Broderick GA Tomaszewski JE, Renshaw AA, Kaplan I, Beard CJ, Wein A. Biochemical outcome after radical prostatectomy, external beam radiation therapy, or interstitial radiation therapy for clinically localized prostate cancer. JAMA. 1998;280:969-74.

26. Huo AS, Hossack T, Symons JL, PeBenito R, Delprado WJ, Brenner P, Stricker PD. Accuracy of primary systematic template guided transperineal biopsy of the prostate for locating prostate cancer: a comparison with radical prostatectomy specimens. J Urol. 2012;187:2044-50.

27. Calio BP, Sidana A, Sugano D, Gaur S, Maruf M, Jain AL, Merino MJ, Choyke PL, Wood BJ, Pinto PA, Turkbey B. Risk of upgrading from prostate biopsy to radical prostatectomy pathology_-does saturation biopsy of index lesion during multiparametric magnetic resonance imaging-transrectal ultrasound fusion biopsy help? J Urol. 2018;199:976-82.

28. Kim SP, Karnes RJ, Mwangi R, van Houten $H$, Gross CP, Gershman B, Leapman MS, Shah ND. Contemporary Trends in Magnetic Resonance Imaging at the Time of Prostate Biopsy: Results from a Large Private Insurance Database. Eur Urol Focus. 2019. https://doi.org/10.1016/j.euf. 2019.03.016.

29. Kasivisvanathan $V$, Rannikko AS, Borghi M, Panebianco V, Mynderse LA, Vaarala MH, Briganti A, Budaus L, Hellawell G, Hindley RG, Roobol MJ, Eggener S, Ghei M, Villers A, Bladou F, Villeirs GM, Virdi J, Boxler S, Robert $G$, Singh PB, Venderink W, Hadaschik BA, Ruffion A, Hu JC, Margolis D, Crouzet S, Klotz L, Taneja SS, Pinto P, Gill I, Allen C, Giganti F, Freeman A, Morris S, Punwani S, Williams NR, Brew-Graves C, Deeks J, Takwoingi Y, Emberton M, Moore CM, PRECISION Study Group Collaboarators. MRI-targeted or standard biopsy for prostate-cancer diagnosis. N Engl J Med. 2018;378:1767-77.

30. Vesey SG, McCabe JE, Hounsome L, Fowler S. UK radical prostatectomy outcomes and surgeon case volume: based on an analysis of the British Association of Urological Surgeons Complex Operations Database. BJU Int. 2012;109:346-54.

31. Laird A, Fowler S, Good DW, Stewart GD, Srinivasan V, Cahill D, Brewster SF, McNeill SA. British Association of Urological Surgeons (BAUS). Contemporary practice and technique-related outcomes for radical prostatectomy in the UK: a report of national outcomes. BJU Int. 2015;115:753-63.

32. Tolonen TT, Kujala PM, Tammela TL, Tuominen VJ, Isola JJ, Visakorpi T. Overall and worst gleason scores are equally good predictors of prostate cancer progression. BMC Urol. 2011;11:21.

\section{Publisher's Note}

Springer Nature remains neutral with regard to jurisdictional claims in published maps and institutional affiliations.

Ready to submit your research? Choose BMC and benefit from:

- fast, convenient online submission

- thorough peer review by experienced researchers in your field

- rapid publication on acceptance

- support for research data, including large and complex data types

- gold Open Access which fosters wider collaboration and increased citations

- maximum visibility for your research: over $100 \mathrm{M}$ website views per year

At $\mathrm{BMC}$, research is always in progress.

Learn more biomedcentral.com/submissions 